\title{
Investigating the potential of humour in EFL classrooms: An attitudinal study
}

\author{
Talip Gonulal \\ Erzincan University, Turkey \\ talip.gonulal@erzincan.edu.tr
}

\begin{abstract}
Studies on humour have indicated that humour has a lot to offer to both language teachers and learners. Creating a positive classroom environment and lowering affective barriers to language learning are among the several effects of humour. However, the appreciation of humour can be culture-specific and context-dependent. For example, greater values may lie in the employment of humour in English as a foreign language (EFL) settings such as Turkey where the communicative-oriented teaching methods are still in their infancy stage. The current study, therefore, examined the potentials of humour from Turkish EFL learners' perspective to elicit their opinions regarding the importance and potent roles of humour in EFL classrooms. In this attitudinal study, a mixed-methods design was used. A comprehensive humour perception questionnaire and semi-structured interviews were employed. Two hundred and fifty college EFL students completed the humour survey and eight of them participated in the follow-up interviews. The results indicated that Turkish college-level EFL students have largely positive attitudes towards using humour in English classrooms. Additionally, students considered humour as an effective pedagogical tool that can increase their attentiveness, attention span, confidence in English classrooms, and teacher-student solidarity, as well.
\end{abstract}

Keywords: humour as a pedagogical tool, language learning, EFL learners, students' beliefs.

\section{Introduction}

The roles and functions of humour in second language (L2) classrooms have been a research topic of increasing interest in recent years. The potential benefits of humour such as drawing attention, increasing motivation, improving retention and reducing anxiety figure notably in L2 humour research conducted in a variety of learning contexts such the US (Askildson 2005), Thailand (Forman 2011) or Vietnam (Petraki \& Nguyen 2016). Given that, the question of whether humour would have the similar impacts in Turkish contexts arises because the traditional teacher-oriented foreign language teaching is still dominating in Turkey. In such teacher-centred environment, language learners may ascribe different meanings and functions to classroom humour or may not consider language classrooms as a 
place where humour can be freely and easily employed. Further, this study aims to provide a better understanding of the potentials of humour in EFL classrooms in the hope that EFL teachers will recognise and appreciate the multi-faceted effects of humour.

\section{Literature review}

Before grappling with research conducted on humour, it is important to first start with the definition of humour. Although there are several different definitions of humour, the element that remains constant across definitions is that humorous communication often includes some kind of incongruity which creates amusement in the end (Martin 2007). Banas, Dunbar, Rodriguez, and Liu (2011) described humour as the use of verbal and nonverbal communication that creates joy and amusement. According to Wagner and Urios-Aparisi (2011: 400), classroom humour is "an act performed through linguistic or nonglinguistic means by any of the participants (i.e., student(s) or teacher)." Based on the key points from the definitions of humour, in this study humour was operationalized as any spoken, written, visual or performed action that the students or teacher find funny or amusing in class, even if it is not inherently funny.

\subsection{Humour in language classrooms}

Humour within general education has been linked to many potential pedagogical benefits beyond providing amusement (Berk 2000; Wanzer \& Frymier 1999; Lovorn \& Holaway 2015; Mantooth 2010; Wanzer, Frymier \& Irwin 2010). For instance, humour is often reported as a useful tool to promote a positive classroom climate, to fight boredom, and to make learning more fun by putting students at ease. In addition, Berk (2000), who investigated the physiological and psychological effects of humour in testing, reported that both undergraduate and graduate students felt that humour was effective in reducing their test anxiety and in helping them perform better in tests. Furthermore, research indicates that classroom humour has the potential to enhance the learning experience (Garner 2006; Torok, McMorris, \& Lin 2004; Wanzer et al. 2010). To illustrate, Wanzer et al. (2010) examined how classroom humour can assist the learning process. Based on the incongruity theory, Wanzer et al. developed the instructional humour processing theory (IHPT). According to the IHPT, learners need to perceive and then resolve the incongruous or bizarre elements in humorous instructional materials so that humour can facilitate learning. In addition, the IHPT proposes that humour or language play has the power to increase learners' attention. Such increased attention can increase the learnability of the input. Further, from a processing perspective, in the process of comprehending humorous materials, the depth of processing often increases (Craik \& Lockhart 1972). That is, incongruous materials are likely to result in "sustained attention and subsequent elaborative processes" (Schmidt \& Williams 2001: 311).

When it comes to humour research in L2 context, Askildson (2005) examined the use of humour as a specific pedagogical tool, and reported that humour was perceived as an important part of the language learning process among both teachers and students. From psychological aspects, several studies (Forman 2011; Petraki \& Nguyen 2016; Reddington 2015; Wagner \& Urios-Aparisi 2011) have shown that teacher-led language play might lessen the language anxiety, and in turn, boost learner engagement in the learning process. Likewise, Pomerantz and Bell (2011) discussed the potential of humour as a 'safe house' for language learning. In looking at the cognitive functions of humour, a number of studies (Bell 2005, 2009, 2012; Bell \& Pomerantz 2014) have shown that language play in L2 education may increase the depth of processing of lexical items and make them "more memorable", and thus can be of great help in language acquisition. More specifically, exploiting humorous 
materials in a variety of ways might lead to L2 learners' sociolinguistic development along with linguistic development. However, Sterling and Loewen (2015), looking at the playful focus on form in teacher-initiated language-related episodes (LREs) in a Spanish classroom, found that the playful LREs were mostly on vocabulary, but less on grammar and pronunciation.

Despite the pedagogical potentials of humour, a possible issue in using humour in a language classroom relates to whether humour will be appreciated or not. That is, what is intended as humorous may not elicit a smile or laugh due to several reasons such as ineffective delivery or a lack of contextual understanding on the part of the listener. In fact, when L2 learners are considered, it is highly likely that most of the humorous situations that induce native speakers to laugh may not have the same effects on L2 learners. According to Schmitz (2002), jokes that address universal elements of humour (e.g. exaggeration, hyperbole, irony etc.) are the easiest to understand for a language learner and can thus be used with beginning level learners, whereas culture-based jokes require higher language proficiency as well as an extensive knowledge of the target culture. On the other hand, linguistic humour calls for high language proficiency to be successfully processed, so it may not be appropriate to use such a type of humour with lower proficiency language learners. Consistent with Schmitz's claim, Bell (2005) found a close relationship between the use of language play and language proficiency. Bell argued that as proficiency level increases, the likelihood of understanding and producing native-like humorous utterances increases correspondingly. In addition to language proficiency, culture may play an important role in comprehending and appreciating humour because the content of humour and perception of what is viewed humorous may vary from culture to culture (Banas et al. 2011). For instance, Chinese students may find classroom humour inappropriate because of the hierarchical order in the instructor-student relationship in Chinese culture, and probably because classroom humour may sometimes make the teaching environment less formal (Zhang 2005).

\subsection{The present study}

As has become apparent in the literature review presented above, several beneficial effects have been linked to the employment of humour in L2 classrooms. However, humour research in EFL contexts, especially in Turkish context is limited. The current situation of English language teaching (ELT) in Turkey constitutes a unique context for humour research for certain reasons. First, although ELT constitutes an important component of the Turkish education system, a number of issues arise at the instructional level probably because of the methods through which English is taught (Kirkgoz 2009). In the light of Turkey's attempts to join the European Union (EU), the ELT policy has gone through several changes to meet EU standards (Kirkgoz 2007, 2009). One of the recent changes in the ELT policy is to adapt the European Language Portfolio, which is consistent with the elements of communicative language teaching (CLT) (Littlewood 1981; Spada 2007). However, English language teachers are still having problems with catching up with the new CLT-oriented ELT system (Alptekin \& Tatar 2011; Ozsevik 2010). Indeed, switching from a long time predominant grammar-translation classroom environment, where the teacher is the main authority in class and takes up much of the speaking time, to a more student-centred approach is not an easy process. As Ozsevik (2010) reported, students, to some extent, show reluctance to take part in communicative activities probably because they get so used to teacher-oriented, lecture-based classrooms.

Considering that humour "has been seen as contributing to a broadening of the parameters of communicative approaches" (Forman 2011: 562), the employment of humour may serve different functions in Turkish context. For instance, the employment of humour 
may repair the one-sided communication in traditional teacher-oriented classroom settings, and make the transition to more student-oriented language teaching easier. The purpose of this study, therefore, was to explore Turkish EFL learners' perspectives on the functions of humour. Specifically, the following research questions guided this study:

1. What roles do Turkish EFL learners assign to humour used in English classrooms?

2. What are Turkish EFL learners' attitudes towards using humour in English language classrooms?

\section{Method}

In this study, a mixed-methods design was employed in which a convergent parallel mixedmethods research design (Creswell \& Plano-Clark 2011) was adapted. That is, both qualitative and quantitative data were collected and analysed separately but the findings were jointly interpreted. The data for this study came from questionnaires and interviews.

\subsection{Participants}

A total of 250 participants from a public university in Turkey took part in this study. Participants were enrolled in an EFL course at various levels. As can be seen in Table 1, participants were majoring in one of the six disciplines (i.e., management, mechanical engineering, electronics, accounting, civil engineering, and economics), with approximately half of them $(45 \%)$ in the management program. Most participants were in either their firstyear $(59 \%)$ or fourth-year $(25 \%)$.

\section{Table 1}

Background information

\begin{tabular}{ccc}
\hline Category & N & $\%$ \\
\hline Gender & 131 & 53 \\
Male & 117 & 47 \\
Female & & \\
Major & 110 & 45 \\
Management & 37 & 15 \\
Mechanical Engineering & 26 & 10 \\
Electronics & 25 & 10 \\
Accounting & 21 & 8 \\
Civil Engineering & 20 & 8 \\
Economics & 11 & 4 \\
Not reported & & \\
Year in College & 147 & 59 \\
Freshman & 15 & 6 \\
Sophomore & 1 & 1 \\
Junior & 63 & 25 \\
Senior & 24 & 10 \\
Not Reported & & \\
\hline
\end{tabular}


Table 2

Additional background information

\begin{tabular}{lcccccc}
\hline Category & $\mathrm{N}$ & $\begin{array}{c}\text { Min } \\
\text { Value }\end{array}$ & $\begin{array}{c}\text { Max } \\
\text { Value }\end{array}$ & Mean & $S D$ & $95 \% C I$ \\
\hline Age & 248 & 18 & 35 & 20.74 & 2.41 & {$[20.44,21.04]$} \\
Age of onset & 247 & 6 & 22 & 10.96 & 2.16 & {$[10.69,11.23]$} \\
Length of learning & 242 & 1 & 16 & 9 & 2.86 & {$[8.64,9.36]$} \\
English & & & & & &
\end{tabular}

Note. $\mathrm{CI}=$ confidence interval

The number of male and female students was approximately the same, $53 \%$ and $47 \%$ respectively. Participants' age ranged from 18 to 35, with an average age of 21 (see Table 2). The mean age at which the participants started learning English was 11, and the mean length of learning English was 9 years.

Participants' self-rated English language proficiency is presented in Table 3, which shows that no skill averaged above 3 out of 6 , with listening being the highest and speaking being the lowest. Finally, participants were asked to rate the amount of humour that their current English instructor was making use of in a typical 50-minute class. Table 4 shows that $79 \%$ of the participants reported that their English instructors were employing humour at least 1-3 times while $11 \%$ of the participants reported their English instructors were never using humour in class.

Table 3

Self-rated English language proficiency for different skills

\begin{tabular}{lcccccc}
\hline $\begin{array}{l}\text { Language } \\
\text { Skills }\end{array}$ & $\mathrm{N}$ & $\begin{array}{c}\text { Min } \\
\text { Value }\end{array}$ & $\begin{array}{c}\text { Max } \\
\text { Value }\end{array}$ & Mean & $S D$ & $95 \% C I$ \\
\hline Reading & 236 & 1 & 6 & 2.78 & 1.27 & {$[2.62,2.94]$} \\
Writing & 235 & 1 & 6 & 2.82 & 1.35 & {$[2.65,2.99]$} \\
Listening & 235 & 1 & 6 & 2.94 & 1.50 & {$[2.75,3.13]$} \\
Speaking & 233 & 1 & 6 & 2.13 & 1.14 & {$[1.99,2.28]$} \\
\hline
\end{tabular}

Note. $1=$ beginner level, $6=$ advanced level. $\mathrm{CI}=$ confidence interval 
Table 4

The frequency of humour use in a one-hour class

\begin{tabular}{lcc}
\hline & $\mathrm{N}$ & $\%$ \\
\hline Never & 16 & 11 \\
1-3 times & 120 & 79 \\
4-7 times & 8 & 5 \\
8-11 times & 0 & 0 \\
12 or more & 8 & 5 \\
Total & 152 & 100 \\
\hline
\end{tabular}

\subsection{Instruments}

A comprehensive 6-point, Likert-scale questionnaire was designed to elicit Turkish EFL learners' perceptions and attitudes regarding the use of humour in English classrooms. As Spada, Barkaoui, Peters, So and Valeo (2009) noted, it is highly important to validate a new or adapted questionnaire before making any claims. The development of the questionnaire used in this study started with a comprehensive literature scan. The only studies that used a humour questionnaire were Askildson (2005) and Mantooth (2010). Further, through a careful analysis of several studies (Bell 2005; Berk 2000; Forman 2011, Wanzer \& Frymier 1999; Lucas 2005; Wagner \& Urios-Aparisi 2011; Wanzer et al. 2010; and others) on the use of humour in classrooms, the potential effects of humour were identified. Then, based on these recurring themes and the questionnaires used in previous studies, a pool of items was created to cover a wide range of aspects of classroom humour. The initial questionnaire contained 35 items but after the necessary changes and edits, the final version of the questionnaire consisted of 25 items (see Appendix A). Then, the questionnaire was translated into Turkish using the forward-backward translation method (Yu, Lee, \& Woo 2004). That is, the questionnaire was first translated into Turkish and then this new Turkish version was translated back into English. The author did the forward translation whereas the backward translation was completed by an advanced Turkish speaker of English. Both translations were reviewed by a native speaker of English who confirmed that the translation of the questionnaire was accurate. Finally, the Turkish version of the questionnaire was piloted with 60 Turkish EFL students. The 25-item questionnaire achieved an alpha coefficient of .88, which was suitable for data collection (Dörnyei \& Taguchi 2009; Field 2013).

The questionnaire data were supported with semi-structured interviews. The interviews were guided by several questions that stemmed from the pilot interviews. Three Turkish graduate students studying at a large Midwestern American University participated in the pilot interviews. These participants had less than three months of ESL experience at the time of the data collection. It was, therefore, assumed that any questions which tapped their English experience were, to a greater extent, related to their previous EFL experience in Turkey. Interview questions initially consisted of twelve open-ended questions which addressed the learners' beliefs and experiences of the use of humour in classroom. After the necessary changes and edits, the final version of the interview questions consisted of 10 items (see Appendix B). 


\subsection{Procedure}

Participants were first contacted through their English instructors. Then, paper-based versions of the questionnaire were distributed to more than 350 students either at the end or at the beginning of English classes. Participants were provided with an operational definition of humour and asked to complete the questionnaire based on their current and previous teachers' teaching practices. The questionnaire took approximately 15 minutes to complete. Interviews were one-on-one and audio-taped. Each interview lasted approximately 20 minutes. The interviews were conducted in Turkish because all the participants preferred speaking Turkish with the author.

\subsection{Analysis}

\subsubsection{Quantitative Analysis}

The questionnaire data underwent a factor analysis to explore the underlying relationships in the participants' questionnaire responses (Field 2013; Loewen \& Gonulal 2015). An exploratory factor analysis ${ }^{1}$ (EFA) was chosen because there were no particular expectations regarding the number and nature of underlying factors that exist in the data. The assumptions of EFA were investigated and met. That is, Cronbach's alpha for the 25 Likert-scale items was .89. Also, the Kaiser-Meyer-Olkin (KMO) test was .879, and the Barlett's test of sphericity was significant $(p<.001)$, all indicating that the data were suitable for a factor analysis (Field 2013). Variables (i.e. items on the questionnaire) with factor loadings larger than .40 were considered significant. The factor extraction method was determined by using multiple criteria (i.e. Kaiser's eigenvalue greater than 1 rule, scree plot and cumulative percentage of variance) to extract the correct number of factors (Loewen \& Gonulal 2015). An oblique rotation ${ }^{2}$ was chosen after the initial factor solution. Special attention was given to complex variables. In other words, the variables that significantly loaded on more than one factor and the variables that did not load any factor were excluded and the analysis was rerun.

\subsubsection{Qualitative Analysis}

The qualitative data were analysed through a phenomenological lens. A phenomenological study "describes the common meaning for several individuals of their lived experiences of a concept or a phenomenon" (Creswell 2013: 76). In relation to the purposes of the present study, this methodology was quite appropriate for investigating EFL learners' beliefs and experiences of humour in English language classroom since this approach provided an indepth description and deeper understanding of Turkish EFL learners' beliefs about the use of humour in English classes. Further, a conversation analytic approach was used for analysis (see Appendix C for transcript conventions).

\section{Results}

\subsection{Quantitative results}

The exploratory factor analysis (EFA) initially produced six factors with eigenvalues greater than 1.0, which accounted for approximately $70 \%$ of the variance. However, after careful analysis of the factor loading matrix, several complex variables were detected. Based on the suggestions of Pett, Lackey and Sullivan (2003), and Loewen and Gonulal (2015), the items loading on more than one factor were deleted for a further exploratory analysis because these 
items were obviously not measuring the intended construct and making the factor labeling process difficult. The second EFA resulted in a four-factor solution, with eigenvalues greater than 1.0. These four factors explained $58.5 \%$ of the variance found in the data, which was in the range of acceptable cumulative percentage level (i.e. 55\%-65\%, Field 2013; Plonsky \& Gonulal 2015). Table 5 displays the factor loadings for the four factors with loadings lower than .40 suppressed.

Also, Table 6 reports the eigenvalues and total variance explained by each factor. The first factor which was labelled desired teacher characteristics contains three items that are associated with EFL learners' preference of humour-oriented teachers. The second factor consists of five items that address a variety of ways in which using humour may lower affective barriers to learning English such as stress and anxiety. The second factor was, thus, labelled low affective filter. The five items that clustered on the third factor are related to the extent humour may increase learners' attentiveness and attention in classroom. This factor was labelled increased attentiveness and attention span. Finally, the last factor concerns the effects of humour on increasing learners' risk-taking in classroom, and was, therefore, labelled increased learner confidence.

Table 5

Rotated factor loadings for humour perceptions

\begin{tabular}{lllllll}
\hline & \multicolumn{5}{c}{ Factors } \\
\cline { 2 - 6 } Item & 1 & 2 & 3 & 4 & $\mathrm{~h}^{2}$ \\
\hline
\end{tabular}

I. Factor 1: Desired Teacher Characteristics

8. I want the English instructor to have a sense of humour.

11. I find English instructors who use jokes more

effective in teaching English.

19. I prefer taking English courses with an English

instructor who uses humour in the classroom

\section{Factor 2: Low Affective Filter}

2. When the English instructor uses humour in the

classroom, I feel my stress level decreases.

4. When the English instructor uses funny examples in the classroom, I feel anxious.

17. I feel more stressed when the English instructor uses funny examples.

18. Having an English instructor who uses humour

reduces my stress about learning English.

20. I feel more comfortable when the English

instructor uses humour in the classroom.

\section{Factor 3: Increased Attentiveness and Attention}

Span

1. I am more attentive in class when the English instructor uses humour.

6. I am more likely to pay attention to the topics 
when the English instructor uses funny examples in the classroom.

10. When the English instructor uses funny

examples, it makes me more interested in learning

English.

13. An English instructor who has a sense of

humour encourages me to learn English.

22. I do not miss an English class when I find the

class funny.

\section{Factor 4: Increased Learner Confidence}

21. I do not feel anxious when I laugh in the

classroom.

23. When the English instructor uses humour in the

classroom, I am not afraid to ask questions.

24. I am not afraid of making mistakes in the

classroom where humour is used frequently.

Mean score for each factor

Note. The negative factor loadings indicate that participants disagreed with the statement in question (e.g. item 4 and item17). The mean score indicates the average response rates for the statements in each factor.

\section{Table 6}

Eigenvalues and total variance explained by each factor

Factor

1. Desired teacher characteristics

2. Low affective filter

3. Increased attentiveness and attention span

4. Increased learner confidence
Initial Eigenvalues

$\begin{array}{ccc}\text { Total } & \text { \% Variance } & \text { Cumulative \% } \\ 5.69 & 35.59 & 35.59 \\ 1.46 & 9.15 & 44.75 \\ 1.15 & 7.18 & 51.93 \\ 1.04 & 6.54 & 58.48\end{array}$

\subsection{Qualitative results}

The Turkish EFL students' beliefs and attitudes regarding the use of humour in English classrooms centred around three themes: (1) the positive impact on teachers, (2) the positive impact on students, and (3) the caution with regard to using humour (see Table 7). These themes will be explained below. 
Table 7

Summary of themes emerged from the interview data

\begin{tabular}{llllccl}
\hline Themes & Examples & Participants & Gender & Age & $\begin{array}{c}\text { LOS } \\
\text { (Yrs.) }\end{array}$ & $\begin{array}{l}\text { Self-rated } \\
\text { proficiency }\end{array}$ \\
\hline $\begin{array}{llllcl}\text { 1.The positive impact } \\
\text { on teachers }\end{array}$ & Excerpt 1 & Ali & Male & 19 & 6 & Fair \\
& Excerpt 2 & Efe & Male & 20 & 7 & Good \\
& Excerpt 3 & Serhat & Male & 20 & 10 & Fair/Good \\
& Excerpt 4 & Mehmet & Male & 23 & 11 & Good \\
\hline 2.The positive impact & Excerpt 5 & Ayhan & Male & 21 & 4 & Poor \\
on students & Excerpt 6 & Serhat & Male & 20 & 10 & Fair/Good \\
& Excerpt 7 & Seda & Female & 19 & 8 & Poor \\
\hline 3.The caution with & Excerpt 8 & Burcu & Female & 21 & 6 & Poor \\
regard to using & Excerpt 9 & Mehmet & Male & 23 & 11 & Good \\
humour & Excerpt 10 & Efe & Male & 20 & 7 & Good \\
& Excerpt 11 & Ali & Male & 19 & 6 & Fair \\
\hline
\end{tabular}

Note. All names are pseudonyms. LOS = Length of L2 study

\subsubsection{The positive impact on teachers}

The first theme that emerged in the interview data was related to interpersonal relationships between the teachers and the students. Four participants-Ali, Efe, Serhat and Mehmetreported their experiences with humorous English teachers, and expressed that there was an increased comfort level with their teachers who made use of different forms of humour while teaching English.

In Excerpt 1, Ali explicitly reported that teachers with a good sense of humour could easily build rapport with students. He also expressed his tendency and desire to better communicate with his teachers.

Excerpt 1 (Ali):

T: Any other potential benefits that you think of?

$\rightarrow \quad$ A: Hhhm (...) well, I think teachers with a good sense of humour are good at communicating with students. We (students) usually behave quite sincere to such teachers.

T: Good point!

A: For instance, I do like being close to my teachers (...) like a friend but not an enemy.

In this excerpt, Ali implicitly stated that teachers who were able to communicate with students were good teachers. Additionally, he was in favour of teacher-student solidarity and teacher immediacy, which teachers with a good sense humour, he seemed to believe, are likely to possess. In a similar vein, in Excerpt 2, Efe related being humorous to being popular. He gave an example that one of his teachers who was funny by nature was welcomed by most of the students, no matter whether they liked the English course or not. 
T: What's his teaching style then?

E: Because he was using some kinds of funny things...especially his gestures and [mimics

T: Hhhm interesting]

$\rightarrow$ E: Yeah he was one of the (...) he was the most popular teacher in that school so:: even if you know you don't like (...) even the students (...) didn't like the English courses they were (.) uhhhm paying attention what the teacher was saying in classroom because they liked him a lot.

This excerpt indicates that the funny situations that teachers create in class break the ice between teachers and students by increasing the feeling of bonding with the teachers. Likewise, in the next excerpt below, Serhat pointed out that when the students liked the teaching style of a teacher, they tended to develop positive feelings towards the course and the teacher as well. Further, Serhat noted that students favoured such teachers and could remember their names even years later.

Excerpt 3 (Serhat):

$\mathrm{T}$ : What was the main reason why you liked that course?

S: Because of the teacher.

$\mathrm{T}$ : Because of the teacher?

S: Yes, he was very good.

T: As a person or as a teacher? Or both? From what aspects was he good?

S: I would say both (...) his classes were very enjoyable (...) how could I express

it? Uhhm I was not shy but very active in the class.

T: Hhhm

S: I could be happy only because I would have an English class.

T: Interesting

$\rightarrow$ S: Uhhm everyone (...) liked that teacher. If someone asked me to name a few teachers that I had had, he would easily be on the top of the list. I think the first thing a teacher should be able to do is to make his students like him and his [teaching] style.

In Excerpt 4, Mehmet reported what kinds of teachers he preferred in class and noted that teachers who used humour, to a lesser or a greater extent, helped introverted and silent students voice their ideas in class.

\section{Excerpt 4 (Mehmet):}

T: From what aspects do you like that class?

M: I mean it includes communication...

$\mathrm{T}$ : Hhm communication?

$\rightarrow \quad$ M: I mean instead of standing in front of the blackboard and writing down sentences on the board, it is better for a teacher to interact with students in a funny way. In such classrooms, even students who do not talk much can join the classroom interaction and may say something.

$\mathrm{T}$ : Hhm it motivates you in some ways?

$\rightarrow \quad \mathrm{M}$ : Yes, it motivates me and I like such teachers a lot.

For a teacher, approachability is a crucial element in a high quality teacher-student relationship. These excerpts indicate that students tend to find humorous teachers more approachable and likeable probably because the humour used in class increases their level of comfort in class and their satisfaction with teachers. Particularly, as some participants stressed, reserved students might find it easier to make connections with teachers who used 
humour in class, which in turn increased their classroom participation and probably positively influenced their learning. These excerpts demonstrate that humour makes teachers seem more humane, and in turn it easily builds the bond between teachers and students.

\subsubsection{The positive impact on students}

Most of the participants interviewed in this study explicitly or implicitly expressed that when their teachers used some forms of humour in class while presenting a grammar topic or teaching vocabulary, they felt that humour in classroom situation affected their attitude towards the course and their learning positively.

In Excerpt 5, the participant, Ayhan, was asked to describe a classroom situation where he found the teacher effective in teaching English. He described how that particular teacher was teaching, and expressed whether he liked his teaching style.

Excerpt 5 (Ayhan):

A: I really liked my English teacher and his teaching methods when I was in the $6^{\text {th }}$ and $7^{\text {th }}$ grades.

T: What was he particularly doing in class? How was his [teaching style?

A: He was a great teacher]

T: I see.

A: He was making use of pictures and cartoon characters a lot in class. Uhhm I don't know but (...) since we were young and [those characters were my favourite ones.

T: Which characters?]

A: Well, uhhm Tom and Jerry, Ninja Turtles.

T: Wow, they are my favourite cartoon characters, too.

$\rightarrow$ A: Yes, he was trying to imitate their voices in a funny way and sometimes explaining or reading the sentences (...) on the board as if he was a cartoon character. Well, he was a great teacher for us actually. I even remember some of the sentences that Jerry said to Tom (changing his voice a bit) Hey, Jerry where were you last night? I was eating cheese uhhm something like that.

$\mathrm{T}$ : It is great that you still remember those dialogues.

A: Well, yes but not all of them.

It seems that the way Ayhan's teacher made use of little jokes and exaggerated gestures in class increased the students' capacity to retain and remember information. Further, Ayhan notes that humour can foster their learning in certain ways, particularly when it is content related. Further support for learning-booster effect of humour is raised by the other two participants who share similar opinions about the positive impacts of humour on students. In Excerpt 6, Serhat explicitly mentioned how a joke can lead to a better understanding of a grammar point by giving an example that the teacher made while explaining where to use 'was' and where to use 'were'.

\section{Excerpt 6 (Serhat):}

T: How might teaching in a funny way help you in an English class?

$\rightarrow$ S: Well, (...) if the jokes that the teacher has made are good, uhhm sometimes we talk about the things that have just happened in the class right after the class...We particularly talk about the interesting ones. For example, before the interview we were talking about the joke that Salih teacher made while teaching uhhm tense (.) past simple tense: Ayvaz was sick ${ }^{3}$.

T: Ohh I see. It was a good joke! 


\section{S: Yeah, I like it!}

Here, the example that Serhat mentioned demonstrates how humour can effectively be incorporated in grammar teaching to draw students' attention to the correct use of 'was/were' and to help them understand the distinction between these two structures. Similarly, the other participant, Seda, noted that her English teacher's humour use in class could create a more comfortable and conducive classroom atmosphere, which in turn might result in an increased student participation in class activities and discussions.

Excerpt 7 (Seda):

T: Hhm good. So, in what ways can humour be beneficial? What might be the possible advantages, for example?

S: Well, uhhm it can [increase

$\mathrm{T}$ : When the teacher makes use of humour]

$\rightarrow \quad$ S: It can help me increase my participation in class.

$\mathrm{T}$ : Hhm you become more active, what else?

$\rightarrow \mathrm{S}$ : The classroom atmosphere might change uhhm (...) sometimes difficult or boring things might be explained and remembered better.

T: Hhhm interesting, any example you can remember?

S: Uhhm (...) I cannot think of (.) any example [right now

$\mathrm{T}$ : It is ok] What else?

These experiences reported in Excerpts 5 through 7 highlight that humour, when used effectively, can be a useful pedagogical tool for drawing students' attention to classroom materials, and encouraging students to take part in classroom activities. Additionally, one of the participants noted that humour could be used as a means of clarifying some classroom materials to enhance students' understanding and learning.

\subsubsection{The caution with regard to using of humour}

Although most of the participants perceived humour as an important component for the language learning process, several participants expressed some cautions against using humour in classrooms effectively. In fact, if not properly used, humour might have some ill effects on learning, as Wandersee (1982: 212) noted:

However, humour is like a stick of dynamite. In an expert's hands it can blast away obstructions between subject matter and student. But in a novice's grasp, it may destroy a lesson just as easily.

In Excerpt 8 below, Burcu noted that humour should be employed with care in order to get the outmost from the employment of humour in classroom. She clearly expressed that the unsuccessful employment of humour may result in several problems.

\section{Excerpt 8 (Burcu):}

$\mathrm{T}$ : What might be the potential disadvantages?

A: Well, if used a lot, it (humour) creates some problem.

T: For example?

$\rightarrow$ A: For example, the teacher may lose the authority in class and uhhm (...) I mean students may not take the classes seriously and even exploit the teacher $\mathrm{T}$ : exploit the good intentions of the teacher?

A: Yes, but apart from these, there are not many disadvantages.

In this excerpt, Burcu drew attention to several severe classroom management problems that might be triggered by ineffective and excessive use of humour. The potential problems that 
Burcu mentioned were related to the teacher losing control of students, and students undervaluing the seriousness of classroom instruction and the teacher's efforts. Apparently, Burcu claimed that the dosage of classroom humour should not be high.

Similarly, in Excerpt 9, Mehmet explained the proportion of humorous time to nonhumorous time in language classrooms, claiming the ratio should be "half to half". Further, he cautioned that if the classroom environment is too relaxing and enjoyable, it might create reverse impact on students.

\section{Excerpt 9 (Mehmet):}

$\mathrm{T}$ : Hhm interesting. If we go back to classroom environment, how would you learn English best in a classroom environment?

$\rightarrow \mathrm{M}$ : Well, in a serious environment...I think it should be half to half. If it is too serious, you may get bored.

T: yeah

$\rightarrow \mathrm{M}$ : But if it is too enjoyable, you may feel you are not learning anything if there is a lot of fun in the class.

T: Yeah good point.

M: So, teachers should make a balance...so for example jokes and funny things should not be used all the time, I mean they should be used but in a timely manner.

Here, Mehmet drew attention to a crucial point by saying "[students] may feel [they] are not learning anything" when humour is used excessively. It seems that humour can be a doubleedged sword; if not used reasonably and timely it can do more harm than good. In the next excerpt, Efe also listed the potential issues that might arise from improper employment of humour and commented on what the appropriate dose of humour should be in a typical class period.

\section{Excerpt 10 (Efe):}

T: Good. Hhmm so how often would you use such jokes?

$\rightarrow$ E: Well, there is a problem here (...) I mean when they (jokes) are used a lot, they lose their power and even students get bored.

T: I agree with you

$\rightarrow$ E: For example, teacher is making jokes so often, students will not take the course seriously $(. .$.$) uhhm students may think that this class is very enjoyable but there$ is nothing much (.) to learn in class.

$\mathrm{T}: \mathrm{Hhhm}$

$\rightarrow$ E: But the jokes that are made at the right time (...) for example 3 or 4 times in a (typical one and a half hour) class (...) uhhm at specific times. For example, after the new topic is explained, the teacher can make use of funny things to help students relax a bit.

In the excerpt above, Efe mentioned several possible problems similar to what Burcu and Mehmet mentioned earlier. In addition, Efe explained that a teacher should employ humour 3 or 4 times at specific time intervals. Likewise, in the next excerpt, Ali underlined that humour, when used extensively, may lose its potential power simply because students may get used to humour.

\section{Excerpt 11 (Ali):}

T: So, what are the disadvantages?

A: I think there is not any.

$\mathrm{T}$ : Are you sure? 
$\rightarrow$ A: Well, (...) maybe it (humour) should not be used in an extensive way (...) because we may find jokes normal uhhhm nothing special (anymore).

Apart from the positive impacts of humour, the participants also discussed what the appropriate use of humour should be in a language class. Most participants stated that if used excessively, humour might have some undesirable effects on the students' attitudes towards the teacher and the course.

\section{Discussion}

In this descriptive and exploratory study, how a particular group of English learners (i.e. Turkish EFL learners) perceived the use of humour in English classrooms was investigated. Two main research questions guided this study. In this section, a result-by-result discussion is not provided because there are several conceptual overlaps between findings. Rather, the results are discussed under three main themes: (a) the positive impact on the relationship between teachers and students, (b) the positive impact on students, and (c) the caution with regard to using humour.

\subsection{The positive impact on the relationship between teachers and students}

The exploratory factor analysis revealed several underlying factors that address Turkish EFL learners' beliefs about the use of humour in English classrooms. The first factor indicates that humour is considered as one of the desirable qualities of teachers. It is interesting to note that on average, the participants agreed more with the statements from Factor 1 (i.e. desired teacher characteristics) than any other factor (see average factor scores in Table 5). In fact, this finding perfectly overlaps with the first theme which emerged from the interviews. That is, almost all the participants interviewed noted that they found teachers with a sense of humour more approachable and likeable. These findings are largely consistent with Wanzer et al.'s (2010) argument that the proper employment of humour increases teacher immediacy. Indeed, teachers with a good sense of humour are often considered to be more effective and therefore tend to be popular with the learners (Lovorn \& Holaway 2015; Petraki \& Nguyen 2016; Torok et al. 2004).

One possible explanation for the high preference among Turkish EFL students for humorous teachers might be mostly related to the current English teaching and learning contexts in Turkey. Several participants in the interviews implicitly stated that the teacheroriented English teaching still persists in Turkey, in which the teacher is the main authority in class and takes up much of the speaking time. In fact, as alluded to in the literature review of this paper, Ozsevik (2010) noted that the grammar-translation method in ELT is still prevailing. In the same vein, Alptekin and Tatar (2011) noted that the employment of communicative-oriented activities has not found its pace in Turkish EFL classroom settings. In such an environment, it is not surprising that the beliefs of Turkish EFL learners about the use of humour are remarkably positive. Considering these points, the participants in this study might have perceived teachers who use humour in class more approachable than other 'traditional' teachers probably because humorous teachers show a different pattern in teaching the subject matter and interacting with students.

\subsection{The positive impact on students}

The results of the quantitative and qualitative data support the notion that humour can have some positive impact on students' attitudes towards the subject matter and on their learning. 
In this study, a large number of Turkish EFL learners perceived humour as a potent pedagogical tool to lower several possible affective barriers (e.g., stress, anxiety, and classroom tension) to language learning. Humour has been reported to be as an important factor in creating a more positive and comfortable classroom environment (Askildson 2005; Garner 2006; Wagner \& Urios-Aparisi 2011). In addition, this positive effect generated through humour may help language learners relieve tension and anxiety. This is clearly reflected in the second factor (i.e. low affective filter) from the exploratory factor analysis. Given that humour has tension-relieving potential, language teachers can make use of it for teaching topics or skills that are usually considered by students as anxiety-inducing (Berk 2000; Forman 2011; Garner 2006; Lucas 2005; Wagner \& Urios-Aparisi 2011).

Similar to previous studies (Askildson 2005; Forman 2011; Petraki \& Nguyen 2016; Wagner \& Urios-Aparisi 2011), the results of the quantitative and qualitative data also indicated that Turkish EFL learners viewed humour as a useful tool to increase their attention to classroom material and to boost their participation in classroom discussions. Further, it is important to note that a large number of learners reported that when humour was employed in class, they tended to take more risks in class, particularly communicating with their teacher or peers. Although this finding has not been reported in any other previous language-focused humour research, one possible explanation for this interesting result might be that the effects generated by humour such as low anxiety level and comfortable classroom atmosphere probably lead to an increased learner confidence in using the target language in class.

Furthermore, several participants in the interviews reported that they felt the successful employment of humour in language teaching helped them better understand the classroom materials, and even increased their capacity to retain and remember the materials presented. This finding aligns with previous humour studies (Jonas 2004; McDaniel, Dornburg, \& Guynn 2005; Petraki \& Nguyen 2016). These studies also showed that the recognition and understanding of humorous materials leads to increased learner attention. This increased attention sequentially increases the learnability of the input. In fact, dealing with humorous materials in a variety of ways can facilitate learning by increasing the depth of processing (Craik \& Lockhart 1972).

\subsection{The caution with regard to using humour}

The results of this study also indicated that although humour has several potential effects on teachers, students and language learning on the whole, it might be fruitless if not used properly. Some cautionary points the participants raised in the interviews are consistent with the suggestions present in humour research on the optimal use of humour in class. For instance, many of the participants opined that excessive use of humour in class does more harm than good probably because there is a saturation point for humour. Several participants mentioned that an extensively relaxed and humorous classroom environment might lead to classroom management problems and a lack of motivation for students towards the course. These comments were not surprising, given that research that shows that routine and excessive use of humour brings about negative impact such as turning learners off (Wanzer 2002), losing the control of the class (Garner 2006; Schmitz 2002), and depreciating the seriousness of instruction (Zhang 2005). Additionally, several participants commented on what the ideal dosage of humour should be in a typical class period. For instance, one participant speculated that employing prepared humorous materials 3 or 4 times in a typical class session might be appropriate. Askildson (2005: 48) described the optimal use of humour as finding the balance between "tension" and "relaxation" in class. Although there are no clear-cut guidelines regarding the appropriate amount humour to be used in class, Sterling and Loewen (2015) found that playful language events occurred only in six percent of 
Spanish as a foreign language class time. In another study, Petraki and Nguyen (2016) reported that Vietnamese EFL teachers tended to use humour at least 7 times in a typical class time. Of course, it is important to note here that humour is not "an easily transportable resource" for teachers to employ in language classrooms like any method or approach of SLA (Reddington, 2015: 34), because humour has the potential "to discomfort or offend...[therefore] should be handled with care" (Forman 2011: 562). Indeed, as Garner (2006) and Schmitz (2002) pointed out that humour could be an effective pedagogical tool only when the teachers use suitable, content-specific and non-offensive humorous materials appropriate for students' level and age.

Although the current study contributes to our understanding of the roles of humour in EFL classrooms, the findings should be interpreted with caution due to some limitations. First, the operationalization of humour was somewhat broad comprising both L1 and L2 humour emanating from the teacher's actions, interaction with students, classroom materials and visual materials that create some forms of positive feelings and amusement on the part of the students. Clearly, considering that humour is socially situated and context driven, a narrower focus on the use of humour (e.g. L2 language play, verbal humour) could provide a more comprehensive description regarding the effects of humour in language classrooms. Further, while the questionnaire revealed some useful insights on participants' beliefs about the use of humour, it treated these beliefs as static and decontextualized. Future studies might focus on a more experimental design by comparing the results of humour-oriented and non-humouroriented instructions. In addition, the current study worked with a relatively homogeneous group of participants coming from the same cultural background. Future research might focus on more culturally-diverse groups of students because the appreciation of humour is also culture-dependent (Zhang 2005).

\section{Conclusion}

This study sought to investigate the use of humour in language classrooms from the perspective of Turkish EFL learners. The quantitative and qualitative findings revealed that Turkish EFL learners had positive attitudes towards the use of humour in English classrooms. Although the current study provides a local perspective regarding the use of humour, the findings can be extrapolated to other EFL contexts where humour can be used as a multifaceted pedagogical tool that can enhance language learning process. For instance, the pedagogical employment of humour in English classrooms can help teachers create a comfortable classroom atmosphere, which consequently constitutes a "safe house" for teaching and learning through lowering the affective filters (Pomerantz \& Bell 2011). Given this particular benefit of humour, employment of humour may offset the one-sided communication in traditional EFL contexts, in particular Turkish EFL settings. Having a humour-oriented teacher who efficiently makes use of humorous materials in class may make EFL learners in such contexts more engaged in classroom communication through developing their socio-cultural and socio-linguistic competences.

Although Forman (2011: 562) highlights that humorous pedagogical style is "created out of the teacher's personal ability and inclination, and attuned to students and context", the largely supportive perceptions of EFL learners in this study may also induce English teachers to develop humour competence (Wulf 2010). For instance, pre-service and in-service teachers might be taught about the skills and method for effectively employing humour in English language classrooms through including a humour session in teacher training. In addition, English teachers might attend workshops that address the various ways to incorporate humour in class. 


\section{Notes}

${ }^{1}$ Although principal components analysis (PCA) might have been produced a simpler factor solution, I have chosen principal axis factoring (PAF) - one of the exploratory factor analysis methods - in this study because my purpose was not pure reduction of variables but to understand the underlying structure in Turkish EFL learners' responses to the humour questionnaire.

${ }^{2}$ In order to obtain a more interpretable factor solution, factors were rotated. Direct oblimin - one of the oblique rotation methods - was chosen because the factors appeared to be correlated.

${ }^{3}$ Ayvaz is a Turkish name and its pronunciation is similar to 'I was'. Therefore, a sentence like 'Ayvaz was sick yesterday' sounds ungrammatical to Turkish EFL learners at first hearing.

\section{Appendix}

\section{Appendix A Humour questionnaire}

\begin{tabular}{|c|c|c|c|c|c|c|c|}
\hline HELL: Humour in English Language Learning & 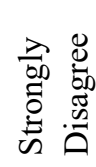 & 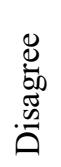 & 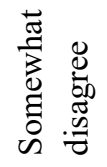 & 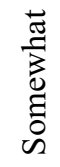 & $\underset{\mathscr{J}}{\stackrel{\Xi}{\sigma}}$ & 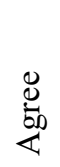 & 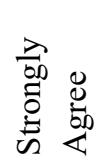 \\
\hline 1. I am more attentive in class when the English instructor uses humour. & 1 & & 3 & & 4 & & 6 \\
\hline $\begin{array}{l}\text { 2. When the English instructor uses humour in the classroom, I feel my stress level } \\
\text { decreases. }\end{array}$ & 1 & & 3 & & 4 & & 6 \\
\hline 4. When the English instructor uses funny examples in the classroom, I feel anxious. & 1 & & 3 & & 4 & & 6 \\
\hline 5. English instructors who use humour in the classroom are unprofessional. & 1 & & 3 & & 4 & & 6 \\
\hline $\begin{array}{l}\text { 6. I am more likely to pay attention to the topics when the English instructor uses funny } \\
\text { examples in the classroom. }\end{array}$ & 1 & & 3 & & 4 & & 6 \\
\hline $\begin{array}{l}\text { 10. When the English instructor uses funny examples, it makes me more interested in } \\
\text { learning English. }\end{array}$ & 1 & & 3 & & 4 & & 6 \\
\hline 11. I find English instructors who use jokes more effective in teaching English. & 1 & & 3 & & 4 & & 6 \\
\hline $\begin{array}{l}\text { 12. I lose my interest in learning English when the English instructor uses humour very } \\
\text { often in the classroom. }\end{array}$ & 1 & & 3 & & 4 & & 6 \\
\hline 13. An English instructor who has a sense of humour encourages me to learn English. & 1 & & 3 & & 4 & & 6 \\
\hline $\begin{array}{l}\text { 14. It is hard to pay attention to the class when the English instructor uses funny } \\
\text { explanations. }\end{array}$ & 1 & & 3 & & 4 & & 6 \\
\hline 15. A funny English instructor decreases my motivation to learn English. & 1 & & 3 & & 4 & & 6 \\
\hline
\end{tabular}




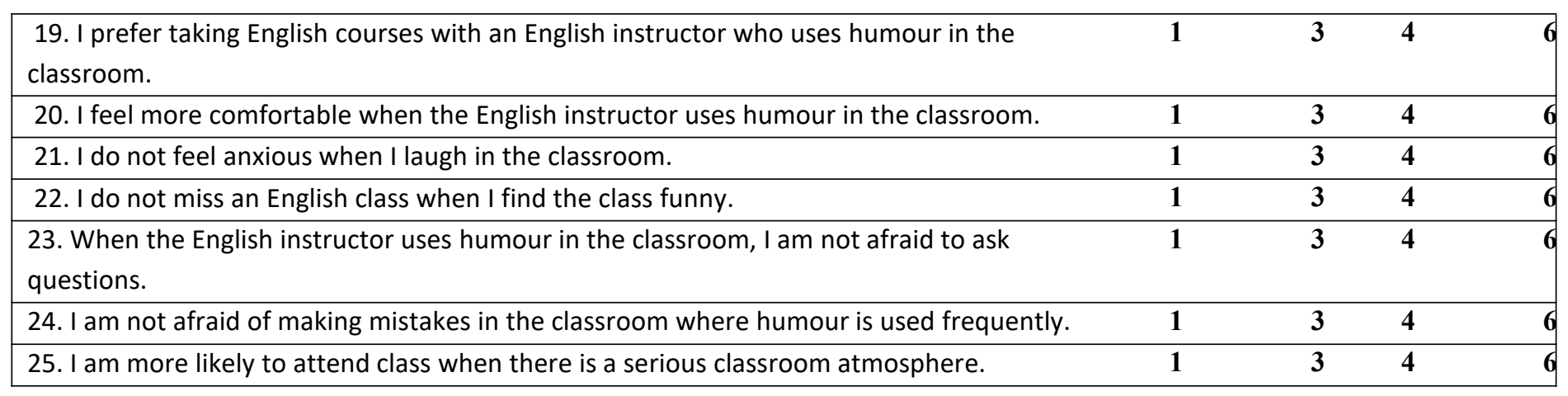

\section{Appendix B: Interview questions}

1. How long have you been learning English and how do you feel about your experience of learning English? Please describe your feelings about your English language classes.

2. Please just try to remember your favorite English class and tell me what you like best about this class.

3. Please try to remember the English class that you liked the least and tell me why you did not like this class.

4. How do you think you can learn English best in an English classroom?

5. What does humour mean to you?

6. How do you think humour can help you learn English?

7. What kinds of humour should a teacher use in class?

8. How do you feel when you cannot understand a joke that your teacher or your peer told?

9. How often should humour be used in a typical classroom time?

10. Do you have any recommendations as to the use of humour in English classrooms?

\section{Appendix C Transcription conventions (Adapted from Belhiah, 2012 and Markee, 2005)}

$T \quad$ represents the interviewer

$E / B$...etcrepresents the interviewees

[ ] indicates the beginning ([) and end (]) of overlapping talk

(.) indicates a short silence (less than $3 \mathrm{~s}$ )

(...) indicates a long silence (more than 3s)

(laughs) indicates non-verbal actions

(?) indicates that some talk was not audible or interpretable at all

$\therefore \quad$ indicates the syllable or the sound is stretched.

- $\quad$ indicates cut off, interruption of a sound

$\rightarrow \quad$ indicates the point of interest in the excerpts

\section{References}

Alptekin, C. \& Tatar, S. (2011). 'Research on foreign language teaching and learning in Turkey (2005-2009)'. Language Teaching 44 (3), pp. 328-353.

Askildson, L. (2005). 'Effects of humour in the language classroom: Humour as a pedagogical tool in theory and practice'. Arizona Working Papers in SLAT 12, pp. 45-61.

Banas, J., A., Dunbar, N., Rodriguez, D. \& Liu, S. J. (2011). 'A review of humour in educational settings: Four decades of research'. Communication Education 60 (1), pp. $115-144$. 
Belhiah, H. (2012). 'You know Arnold Schwarzenegger? On doing questioning in second language dyadic tutorials'. Applied Linguistics 33 (1), pp. 21-41.

Bell, N. (2005). 'Exploring L2 language play as an aid to SLL: A case study of humour in NSNNS interaction'. Applied Linguistics 26 (2), pp. 192-218.

Bell, N. (2009). 'Learning about and through humour in the second language classroom'. Language Teaching Research 13 (3), pp. 241-258.

Bell, N. (2012). 'Comparing playful and nonplayful incidental attention to form'. Language Learning 62 (1), pp. 236-265.

Bell, N. \& Pomerantz, A. (2014). 'Reconsidering language teaching through a focus on humour'. EuroAmerican Journal of Applied Linguistics and Languages 1 (1), pp. 31-47.

Berk, R. (2000). 'Does humour in course tests reduce anxiety and improve performance?' College Teaching 48 (4), pp. 151-159.

Craik, F. I. M. \& Lockhart, R. (1972). 'Levels of processing: A framework for memory research'. Journal of Verbal Learning and Verbal Behavior 11, pp. 671-684.

Creswell, J. W. (2013). Qualitative Inquiry and Research Design: Choosing among Five Approaches. Los Angeles, CA: SAGE.

Creswell, J. W. and Plano-Clark, V. L. (2011). Desigining and Conducting Mixed Methods Research ( $2^{\text {nd }}$ ed.). Thousand Oaks, CA: SAGE Publishing.

Dörnyei, Z. \& Taguchi, T. (2009). Questionnaires in Second Language Research: Construction, Administration, and Processing ( $2^{\text {nd }}$ ed.). New York: Routledge.

Field, A. (2013). Discovering Statistics Using IBM SPSS Statistics. London: Sage.

Forman, R. (2011). 'Humorous language play in a Thai EFL classroom'. Applied Linguistics 32 (5), pp. 541-565.

Garner, R. L. (2006). 'Humour in pedagogy: How ha-ha can lead aha!' College Teaching 54 (1), pp. 177-180.

Jonas, P. M. (2004). Secrets of Connecting Leadership and Learning with Humour. Maryland: Rowman \& Littlefield Publishing Group Inc.

Kirkgoz, Y. (2007). 'English language teaching in Turkey: Policy changes and their implementations'. RELC Journal 38 (2), pp. 216-228.

Kirkgoz, Y. (2009). 'Globalization and English language policy in Turkey'. Educational Policy 23 (5), pp. 663-684.

Littlewood, W. (1981). Communicative Language Teaching: An Introduction. Cambridge: Cambridge University Press.

Loewen, S. \& Gonulal, T. (2015). 'Exploratory factor analysis and principal components analysis', in Plonsky, L. (Ed), Advancing Quantitative Methods in Second Language Research. New York: Routledge, pp. 182-212.

Lovorn, M. \& Holaway, C. (2015). 'Teachers' perceptions of humour as a classroom teaching, interaction, and management tool'. European Journal of Humour Research 3 (4), 24-35.

Lucas, T. (2005). 'Language awareness and comprehension through puns among ESL learners'. Language Awareness 14 (4), pp. 221-238.

Mantooth, J. D. (2010). 'The effects of professor humour on college students' attention and retention'. Doctoral dissertation, Auburn University.

Markee, N. (2005). 'Conversation analysis forsecond language acquisition', in Hinkel, E. (Ed), Handbook of Research in Second Language Teaching and Learning, Vol. 1. NJ: Lawrence Erlbaum Mahwah, pp. 355-374.

Martin, R. A. (2007). The Psychology of Humour: An Integrative Approach. Cambridge: Cambridge University Press.

McDaniel, M., Dornburg, C. \& Guynn, M. (2005). 'Disentangling encoding versus retrieval explanations of the bizarreness effect: Implications for distinctiveness'. Memory and Cognition 33, pp. 270-279. 
Ozsevik, Z. (2010). 'The use of communicative language teaching (CLT): Turkish EFL teachers' perceived difficulties in implementing CLT in Turkey'. Master's thesis, University of Illinois at Urbana-Champaign.

Pett, M. A., Lackey, N. R. \& Sullivan, J. J. (2003). Making Sense of Factor Analysis: The Use of Factor Analysis for Instrument Development in Health Care Research. Sage.

Petraki, E. \& Nguyen, H. H. P. (2016). 'Do Asian EFL teachers use humour in the classroom? A case study of Vietnamese EFL university teachers'. System 61, pp. 98-109.

Plonsky, L. \& Gonulal, T. (2015). 'Methodological synthesis in quantitative L2 research: A review of reviews and a case study of exploratory factor analysis'. Language Learning, 65 (S1), pp. 9-36.

Pomerantz, A. \& Bell, N. D. (2011). 'Humour as safe house in the foreign language classroom'. The Modern Language Journal 95 (1), pp. 148-161.

Reddington, E. (2015). 'Humour and play in language classroom interaction: A review of the literature'. Teachers College, Columbia University Working Papers in TESOL \& Applied Linguistics 15 (2), pp. 22-38.

Schmidt, S. \& Williams, A. (2001). 'Memory for humorous cartoons'. Memory and Cognition 29, pp. 305-311.

Schmitz, J. R. (2002). 'Humour as a pedagogical tool in foreign language and translation courses'. International Journal of Humour Research 15 (1), pp. 89-113.

Spada, N. (2007). 'Communicative language teaching: Current status and future prospects', in Jessner, U. \& Cenos, J. (Eds.), International Handbook of English language teaching. New York: Springer, pp. 271-288.

Spada, N., Barkaoui, K., Peters, C., So, M. \& Valeo, A. (2009). 'Developing a questionnaire to investigate second language learners' preferences for two types of form-focused instruction'. System 37 (1), pp. 70-81.

Sterling, S. \& Loewen, S. (2015). 'The occurrence of teacher-initiated playful LREs in a Spanish L2 classroom'. System 53, pp. 73-83.

Torok, E. S., McMorris, F. R. \& Lin, W. (2004). 'Is humour an appreciated teaching tool? Perceptions of professors' teaching styles and use of humour'. College Teaching 52 (1), pp. 14-20.

Wagner, M. \& Urios-Aparisi, E. (2011). 'The use of humour in the foreign language classroom: Funny and effective?' Humour: International Journal of Humour Research 24 (4), pp. 399-434.

Wandersee, J. H. (1982). 'Humour as a teaching strategy'. American Biology Teacher 44 (4), pp. 212-18.

Wanzer, B. M. (2002). 'Use of humour in the classroom: The good, the bad and the not-so funny things that teachers say and do'. Communication for Teachers. Boston: Allyn and Bacon.

Wanzer, B. M. \& Frymier, A. B. (1999). 'The relationship between student perceptions of instructor humour and students' reports of learning'. Communication Education 48, pp. $48-62$.

Wanzer, B. M., Frymier, A. B. \& Irwin, J. (2010). 'An explanation of the relationship between instructor humour and student learning: Instructional humour processing theory'. Communication Education 59 (1), pp. 1-18.

Wulf, D. (2010). 'A humour competence curriculum'. TESOL Quarterly 44 (1), pp. 155-169.

Zhang, Q. (2005). 'Immediacy, humour, power distance, and classroom communication apprehension in Chinese college classrooms'. Communication Quarterly 53, pp. 109-124.

$\mathrm{Yu}, \mathrm{D}$. S., Lee, D. T., \& Woo, J. (2004). 'Issues and challenges of instrument translation'. Western Journal of Nursing Research 26 (3), pp. 307-320.. 